\title{
Dynamic High-Temperature Tensile Characterization of an Iridium Alloy with Kolsky Tension Bar Techniques
}

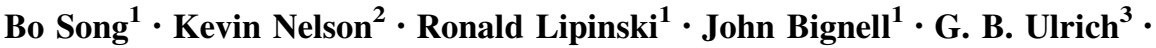 \\ E. P. George ${ }^{3}$
}

Received: 5 February 2015/Accepted: 9 May 2015/Published online: 29 May 2015

(C) Society for Experimental Mechanics, Inc. (outside the US) 2015

\begin{abstract}
Conventional Kolsky tension bar techniques were modified to characterize an iridium alloy in tension at elevated strain rates and temperatures. The specimen was heated to elevated temperatures with an induction coil heater before dynamic loading; whereas, a cooling system was applied to keep the bars at room temperature during heating. A preload system was developed to generate a small pretension load in the bar system during heating in order to compensate for the effect of thermal expansion generated in the high-temperature tensile specimen. A laser system was applied to directly measure the displacements at both ends of the tensile specimen in order to calculate the strain in the specimen. A pair of high-sensitivity semiconductor strain gages was used to measure the weak transmitted force due to the low flow stress in the thin specimen at elevated temperatures. The dynamic hightemperature tensile stress-strain curves of a DOP-26 iridium alloy were experimentally obtained at two different strain rates $\left(\sim 1000\right.$ and $\left.3000 \mathrm{~s}^{-1}\right)$ and temperatures $\left(\sim 750\right.$ and $\left.1030^{\circ} \mathrm{C}\right)$. The effects of strain rate and temperature on the tensile stress-strain response of the iridium alloy were determined. The iridium alloy exhibited high ductility in stress-strain response that strongly depended on strain-rate and temperature.
\end{abstract}

Keywords Kolsky bar $\cdot$ High temperature $\cdot$ Dynamic tension $\cdot$ Iridium alloy $\cdot$ Stress-strain response

Bo Song

bsong@sandia.gov

Sandia National Laboratories, Albuquerque, NM 87185, USA

Sandia National Laboratories, Livermore, CA 94550, USA

Oak Ridge National Laboratory, Oak Ridge, TN 37831, USA

\section{Introduction}

Iridium alloys possess unique property combinations of high melting temperature, high-temperature strength and ductility, and excellent oxidation and corrosion resistance [1], making them ideal for high-temperature applications. In some applications, the high-temperature impact response of the material must be fully understood in order to meet the safety requirements for the design of components. High-strain-rate and high-temperature stressstrain data are thus needed to develop strain-rate and temperature dependent material models for safety analysis. However, current mechanical characterization of iridium alloys has been limited to relatively low strain rates (below $50 \mathrm{~s}^{-1}$ ) [2-5], which are not sufficiently high for their potential applications. Song et al. [6, 7] recently employed Kolsky compression bar testing, also known as split Hopkinson pressure bar testing, to characterize the compressive stress-strain properties of a DOP-26 iridium alloy at high strain rates $\left(300-10,000 \mathrm{~s}^{-1}\right)$ and high temperatures $\left(750\right.$ and $\left.1030{ }^{\circ} \mathrm{C}\right)$. The iridium alloy showed significant strain-rate and temperature effects on the compressive stress-strain response. However, the compression tests did not provide ductility and failure information at high strain rates and temperatures. Therefore, dynamic tensile characterization of iridium alloys at high temperatures was needed.

The Kolsky bar was originally developed for compression testing [8] and subsequently modified for use in tension and torsion testing $[9,10]$. A variety of Kolsky tensile bar techniques have been developed since the 1960s [11]. The most commonly used method is direct-tension Kolsky bars [12, 13]. Recently, Song et al. [14] developed a directtension Kolsky bar that launches a solid striker to an end cap on the open end of the gun barrel to generate a dynamic 
tensile load in the bar system. In contrast to the compression tests, more attention must be paid to the Kolsky tensile tests due to the complication of specimen attachment to the bar ends. A dog-bone-shaped cylinder with threads on both ends is a typical specimen design for Kolsky tension bar tests. However, special fixtures are needed when characterizing thin sheet specimens like the iridium specimen investigated in this study. In addition, the complex specimen fixtures may modify the stress wave propagation. For instance, a stress wave reflection may be generated at each interface within the joints/fixtures between the specimen and the bars. In this case, the reflected wave, which is usually used to calculate the strain rate and strain in the specimen, is no longer reliable. Direct displacement measurements, i.e. non-contact optical measurements, on both ends of the specimen are preferred.

It has been very challenging to conduct hightemperature Kolsky tension bar experiments. For hightemperature Kolsky bar tests, which are typically in compression, it is a common practice to heat the specimen individually while the whole bar system is kept at room temperature before dynamic loading. The high-temperature specimen is dynamically loaded immediately upon contact with the room-temperature bars. Cold contact time (CCT) has been defined as the time during which the high-temperature specimen stays in contact with the room-temperature bars until being dynamically loaded [11]. The CCT is usually required to be as short as several milliseconds, and even within $1 \mathrm{~ms}$ when the specimen is thin [7]. Appropriate modifications have been made to Kolsky compression bars for generating short CCTs. However, it has been difficult to directly apply these modifications to Kolsky tension bars. In a Kolsky tension bar test, the specimen has to be firmly attached to the bar ends before dynamic loading, which makes it nearly impossible to heat the specimen individually. Su et al. [15] applied a layer of thermal-protective coating with a very low heat transfer coefficient to the bar surface to mitigate the heat transfer to the bars. Using the same method, the temperature in the bars was reduced to below $300{ }^{\circ} \mathrm{C}$ when the specimen was heated to $527^{\circ} \mathrm{C}$ [16]. This means the heat was still transferred from the high-temperature specimen to the bars through the threads, which generated a thermal gradient in the bars. Such a thermal gradient may become more significant when the testing temperature increases. A significant thermal gradient will result in erroneous stress and strain measurements in the specimen, particularly when the test temperature is over $600{ }^{\circ} \mathrm{C}$ where the Young's modulus of steel, a typical bar material, decreases significantly. These challenges limit current Kolsky tension bar tests to temperatures below $600{ }^{\circ} \mathrm{C}$ [15-19], where the effects of temperature gradients on the steel bars can be neglected [18]. However, special experimental design considerations are required for Kolsky tension bar experiments at higher temperatures, i.e., 750 and $1030{ }^{\circ} \mathrm{C}$ in this study.

In this study, the conventional Kolsky tension bar was modified to characterize dynamic tensile stress-strain response of a thin-sheet DOP-26 iridium alloy at elevated temperatures. The iridium alloy was characterized at two different strain rates $\left(\sim 1000\right.$ and $\left.3000 \mathrm{~s}^{-1}\right)$ and temperatures $\left(\sim 750\right.$ and $\left.1030{ }^{\circ} \mathrm{C}\right)$ in order to determine the effects of strain rate and temperature on the tensile stressstrain response.

\section{Modified High-Temperature Kolsky Tension Bar System}

The Kolsky tension bar described in [14] was modified in this study for dynamic high-temperature characterization of the DOP-26 iridium alloy. Figure 1 shows a schematic of the modified high-temperature Kolsky tension bar system. Since it is not possible to directly thread a thin and flat iridium specimen into the bar ends, a pair of specimen fixtures was designed, as shown in Fig. 2a. This design used a flat dog-bone shaped tensile specimen which is similar to the one used in Ref. [20]. The fixture was machined with a slot with the same dimensions as the nongage section of the specimen such that the whole non-gage section of the specimen was placed into the slot of the fixture. This design allows the specimen shoulder take the load and transfer it to the specimen gage section. In addition, the area of the shoulder was much larger than that of the specimen gage section (Fig. 2a). The deformation in the non-gage section (shoulder) was therefore minimized during dynamic loading. The specimen was then covered with a semicircular cap. The depth of the fixture was made the same as the specimen thickness such that the semicircular cap did not provide additional perpendicular force on the specimen but retained the specimen during dynamic loading. Both the fixtures and the semicircular caps were made of Inconel 718 steel, which has a relatively high strength at elevated temperatures.

An induction coil heater, which was first applied by Rosenberg et al. [21] for high-temperature Kolsky bar experiments, was installed on the testing section. Due to the small size of the specimen under investigation, the induction coil was set to heat the relatively large fixtures and then transfer the heat to the specimen (Fig. 2b). This experimental design enabled direct measurement of displacements at the specimen ends using a laser extensometer. When the fixtures were heated with the induction coil, the heat was transferred to both the specimen and the bars simultaneously. In order to prevent heating of the bars, a pair of hollow water-cooled pillow blocks was installed on the bar ends, as shown in Fig. 2c. This design is similar 
Fig. 1 Illustration of hightemperature Kolsky tension bar setup

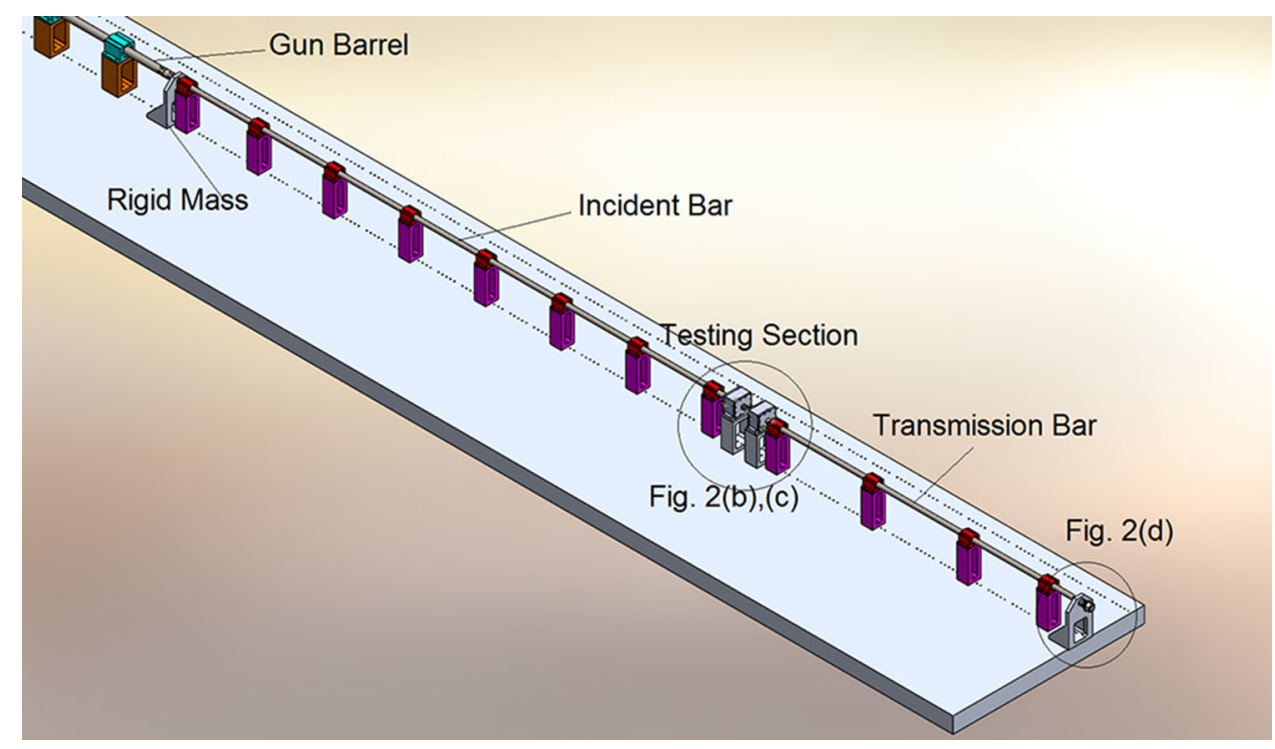

(a)

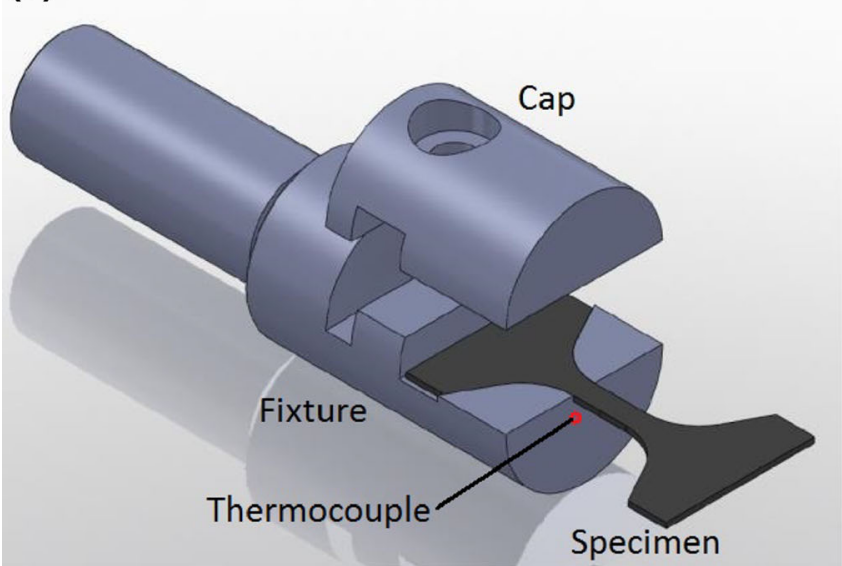

(c)

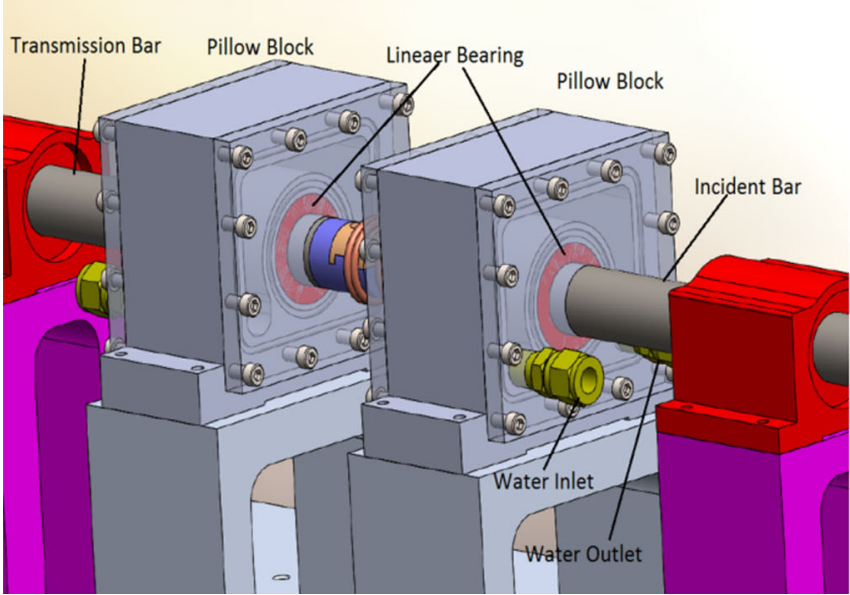

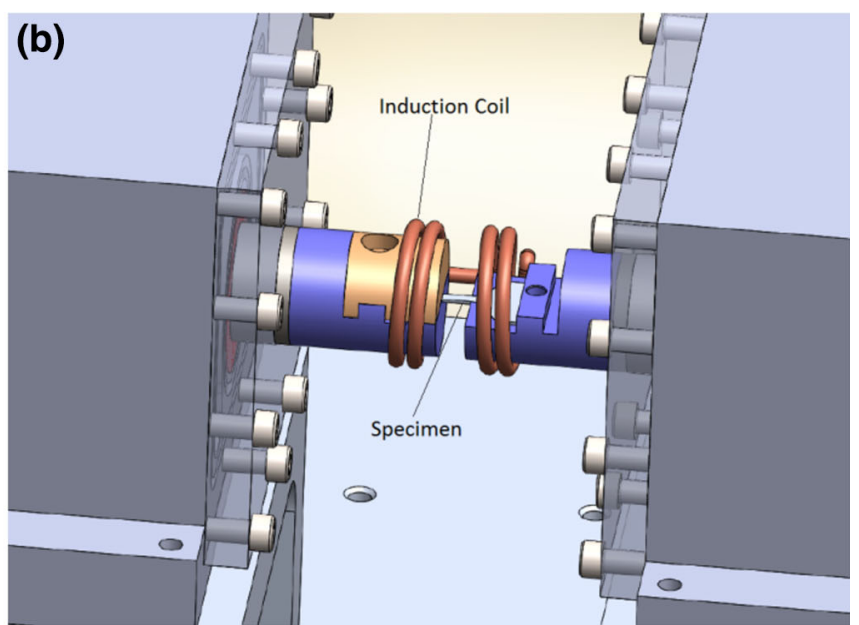

(d)

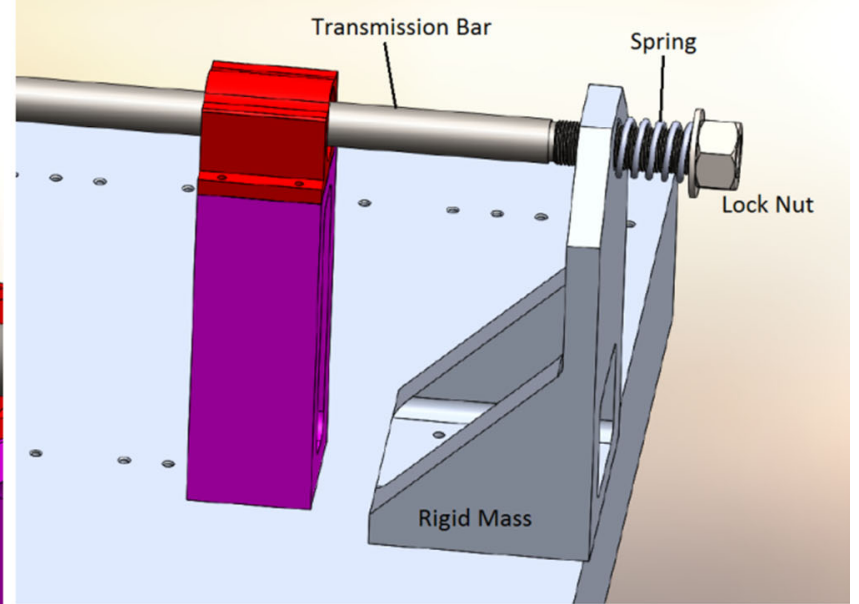

Fig. 2 Details of the high-temperature Kolsky tension bar design. a Specimen and fixture design; b induction coil design; c cooling system design; d spring pre-tension load design 
in principle to that developed by Scapin et al. [22]. The difference is that Scapin et al. [22] applied a Cortex-tubebased air cooling system to cool down the bars for testing up to $400{ }^{\circ} \mathrm{C}$. The water cooling system used in this study was proven to be capable of cooling the bars below room temperature when the testing temperature was as high as $1030{ }^{\circ} \mathrm{C}$.

As shown in Fig. 2b, the high-temperature fixtures attached to the bar ends still generated a thermal gradient between the bars and the specimen even though the bars were kept at room temperature, which might modify the wave propagation. In addition, the complicated design of the fixtures themselves exhibited many interfaces that might also modify the wave propagation. Both resulted in an unreliable reflected pulse for specimen strain calculation. As mentioned earlier, we employed a laser system to directly measure the displacement histories at the specimen ends of the fixtures. Non-contact laser systems have been recently used for direct displacement measurements in Kolsky bar experiments [23, 24]. The splitting-beam laser extensometer presented in Ref. [24] was employed in this study to independently measure the displacements at both ends of the specimen.

The working principle of the laser system is illustrated in Fig. 3. A uniform laser line generator was used as a light source and then split into two independent beams. The movements of the incident and transmission bars, which consequently stretch the specimen, generate the intensity changes of the laser beams that are independently detected with two separate laser detectors. The laser detector used in this study had a bandwidth of $100 \mathrm{kHz}$ or even higher, depending on the resolution, which is sufficiently high for Kolsky bar experiments. The resolutions of the laser detectors were able to be set independently to further increase the accuracy of the specimen strain measurement. In this study, the laser detectors have been calibrated to exhibit a perfect linearity but with different factors: $0.732 \mathrm{~mm} / \mathrm{v}$ at the incident bar side and $0.258 \mathrm{~mm} / \mathrm{v}$ at the transmission bar side. The specimen strain can be calculated as

$\varepsilon=\frac{L_{1}-L_{2}}{L_{s}}$,

where $L_{1}$ and $L_{2}$ are displacements of the specimen ends attached to the incident and transmission bars, respectively; $L_{s}$ is the gage length of the specimen. As shown in Fig. 1a, the non-gage sections of the specimen were enclosed in the fixtures. Equation (1) maximizes the representation of the actual deformation of the gage section without the need for correction with respect to the deformation in the non-gage sections.

When the thin iridium specimen was heated, i.e. to 750 and $1030{ }^{\circ} \mathrm{C}$ in this study, the specimen became longer due to thermal expansion. However, the force generated by such a thermal expansion was not sufficiently high to overcome the friction between the bars and the bar supports and to push the incident and transmission bars back. As a consequence, the thin iridium specimen was buckled, which produced an erroneous stress-strain response and was difficult to correct numerically. A spring-loaded pretension system, as shown in Fig. 2d, was developed to prevent the specimen from buckling during heating. The spring was placed between a rigid mass and a flange (Fig. 2d). The flange was screwed toward the rigid mass to compress the spring, which in turn generated a tension load in the tension bar system including the tensile specimen. Another rigid mass was placed against the gun barrel (Fig. 1) to prevent the bar system from moving backwards when the whole bar system was pre-loaded in tension [25]. In this study, the spring was set to generate a pre-tension load of approximately $18 \mathrm{~N}$ which is sufficient to straighten the iridium specimen during heating but insufficient to produce further stretch on the iridium specimen.

Another high temperature testing issue is thermal softening of the specimen. In general, the flow stress in
Fig. 3 The splitting-beam laser extensometer for bar-end displacement measurement

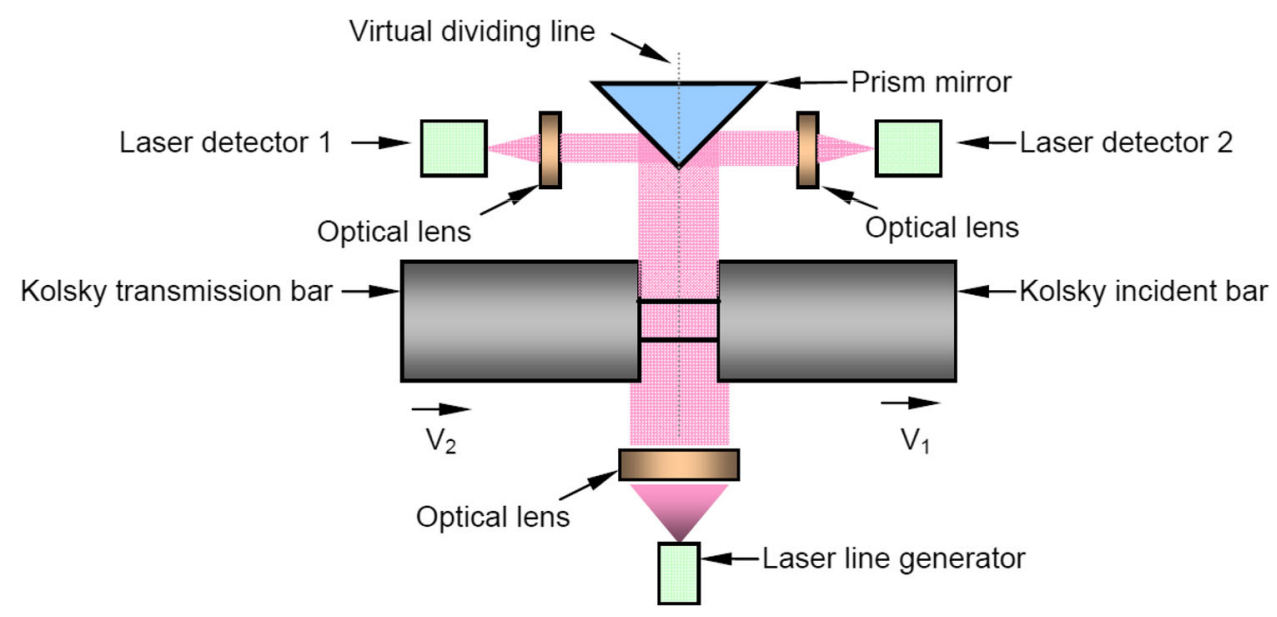


metallic materials decreases significantly at elevated temperatures, which results in a very weak transmitted signal in Kolsky bar experiments. In order to measure the weak transmitted signal with relatively high resolution, a pair of semiconductor strain gages was used to replace the regular resistor strain gages on the transmission bar. The semiconductor strain gages had a gage factor of 139 , which is approximately 70 times more sensitive than the regular resistor strain gages. The specimen stress is calculated as

$\sigma=\frac{E_{0} A_{0} \varepsilon_{t}}{A_{s}}$

where $E_{0}$ is Young's modulus of the bar material; $A_{0}$ is the cross-sectional area of the transmission bar; $\varepsilon_{t}$ is the transmitted strain; and $A_{s}$ is the cross-sectional area of the specimen.

Combining the measurements of the semiconductor strain gages (Eq. 2) and the laser system (Eq. 1) for specimen stress and strain histories, respectively, yields the stress-strain curve of the specimen under investigation.

\section{Dynamic High-Temperature Tensile Characterization of Iridium Alloy}

The material investigated in this study was DOP-26 iridium alloy which contains iridium as the base material alloyed with nominally $0.3 \mathrm{wt} \%$ tungsten, $60 \mathrm{wppm}$ thorium, and 50 wppm aluminum $[3,4]$. The iridium tensile specimens were removed from prime DOP-26 alloy blanks using electrical discharge machining (EDM) with zinc-coated brass wire. The specimens were ground to remove the residual EDM layer, and then deburred and polished. All specimens were acid cleaned and then annealed at $1375{ }^{\circ} \mathrm{C} \pm 25{ }^{\circ} \mathrm{C}$ for $1 \mathrm{~h} \pm 10 \mathrm{~min}$ in vacuum $\left(1 \times 10^{-4}\right.$ torr), producing an average grain size of approximately $25 \mu \mathrm{m}$. Typical annealed DOP-26 iridium alloy microstructures may be found in Ref. [5]. The tensile specimens had a thickness of $0.66 \mathrm{~mm}$, a width of $2.54 \mathrm{~mm}$, and a gage length of $6.35 \mathrm{~mm}$. The specimen thickness was specified to match the thickness of interest for the applications. The detailed dimensions of the iridium specimens used in this study are shown in Fig. 4. In this study, the DOP-26 iridium alloy was dynamically characterized at 750 and $1030{ }^{\circ} \mathrm{C}$, which are approximately 38 and $48 \%$ of the melting temperature $\left(2446{ }^{\circ} \mathrm{C}\right)$ of pure iridium, respectively.

In order to check the temperature uniformity in the specimen during heating, three thermocouples were attached to the gage section of the iridium specimen: one was placed in the center and the other two were placed close to each end of the specimen, respectively, as shown in Fig. 5a. Figure $5 \mathrm{~b}$ shows the temperature histories from the

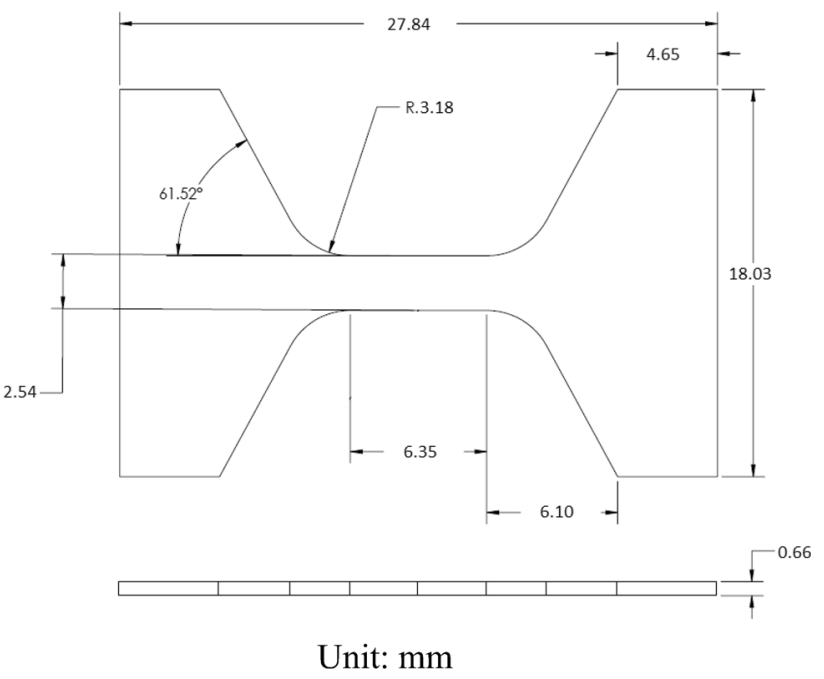

Fig. 4 Iridium tensile specimen

three thermocouples when the induction heater was programmed to heat the specimen to $750{ }^{\circ} \mathrm{C}$. The thermocouple signals were noisy with high frequencies caused by the electromagnetic field generated by the induction coil. In order to provide clearer temperature readings, a $10 \mathrm{~Hz}$ digital filter was applied to the thermocouple signals, the results of which are also shown in Fig. 5b. It is noted that Fig. $5 \mathrm{~b}$ records the whole heating process of the specimen. However, it takes much less time, usually 3-4 s (called "time window of testing" here), to complete the dynamic testing procedure, as marked in Fig. 5c. The temperatures were very consistent during the heating process as indicated by the thermocouples in these three different locations. The results demonstrate the reasonable uniformity of the temperature across the whole specimen gage section $\left(756 \pm 17^{\circ} \mathrm{C}\right)$. In actual iridium alloy testing, only one thermocouple was attached to the fixture surface under the specimen, as shown in Fig. 2a, to avoid spot welding the thermocouple to the surface and causing specimen microstructure changes.

Figure 6 shows typical strain gage signals on the incident and transmission bars for the incident, reflected, and transmitted waves at the test temperature of $1030{ }^{\circ} \mathrm{C}$. As shown in Fig. 6, the transmission bar strain was low (only 15 microstrains) due to the low strength of the iridium specimen at such a high temperature. High resolution measurement of the low transmitted signal was achieved by using high sensitivity semiconductor strain gages. Again, the reflected pulse was not reliable and could not be used for specimen strain measurement. Instead, we used the laser system (Fig. 3) to directly track the movements of the specimen ends that were attached to the incident and transmission bars. The laser outputs are shown in Fig. 7. Figure 7 clearly shows significant change in the laser 
(a)
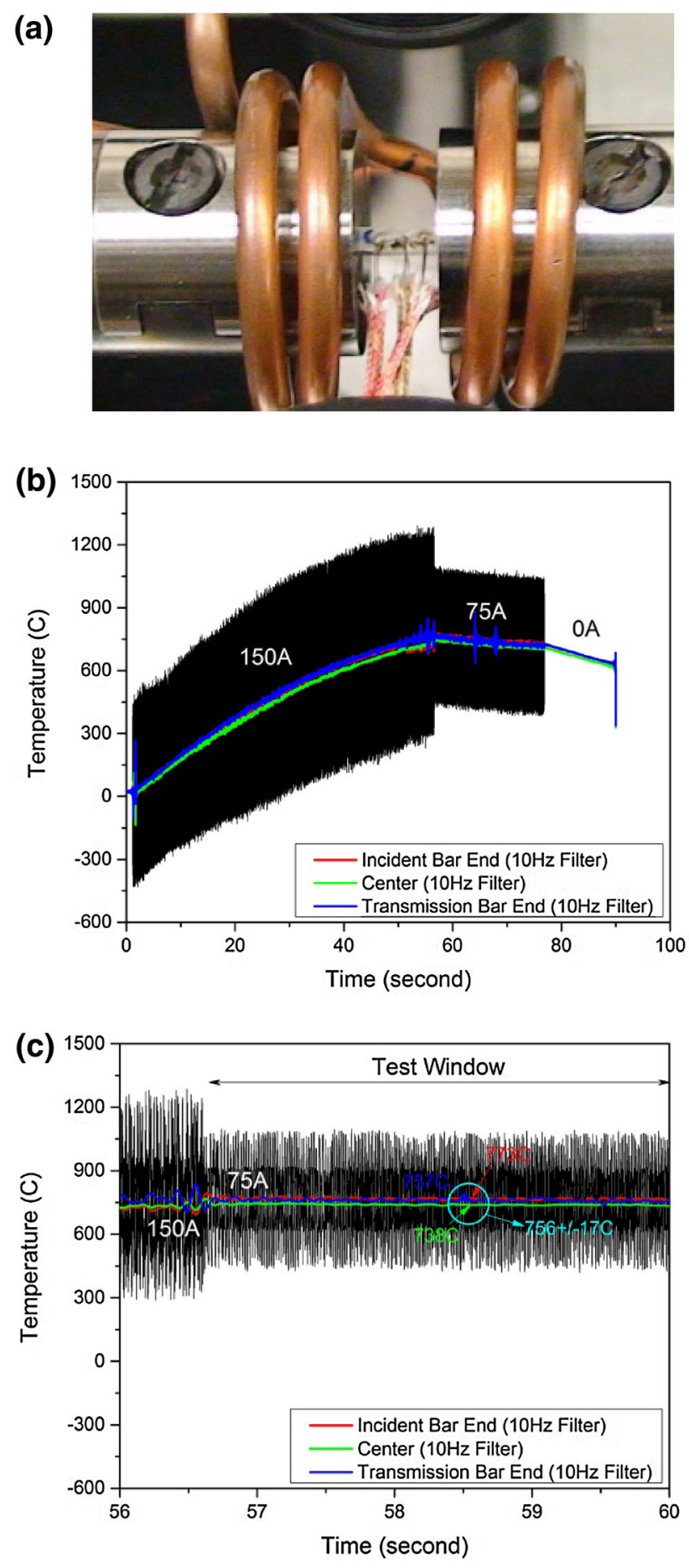

Fig. 5 Temperature uniformity during induction heating. a Induction coil and thermocouple locations; $\mathbf{b}$ temperatures recorded at three different locations; $\mathbf{c}$ temperatures over the duration of dynamic test

output for the front end (on the incident bar side) but no significant change for the back end (on the transmission bar side). This is because the transmitted force was too small to generate significant displacement on the transmission bar side.

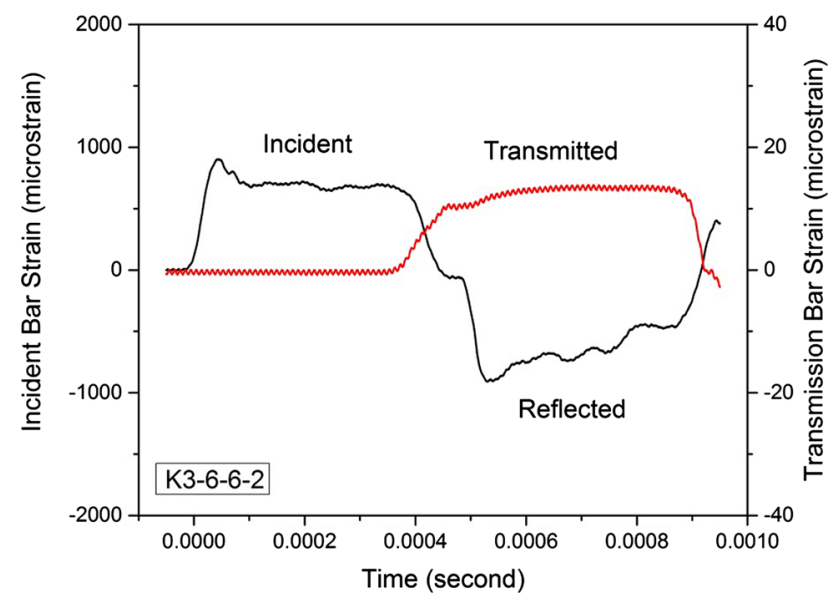

Fig. 6 Typical incident, reflected, and transmitted signals

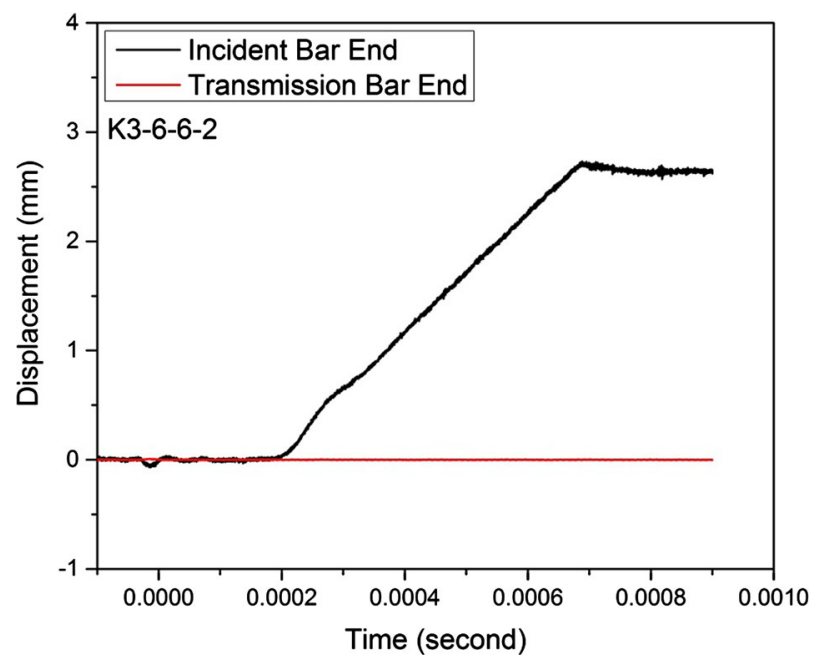

Fig. 7 Laser outputs for bar-end displacement measurements

The engineering stress and strain histories in the specimen, which were calculated with Eqs. (2) and (1), respectively, are shown in Fig. 8. The strain rate was then calculated with the slope of the strain history as a nearly constant $860 \mathrm{~s}^{-1}$. It is noted that when the reflected pulse becomes unreliable, it is difficult to compare the force histories at both ends of the specimen for force/stress equilibrium checks. In this study, we conducted preliminary tests with high-rate high-temperature digital image correlation (DIC) approaches to qualitatively check the deformation uniformity across the whole specimen gage section. The DIC results showed that, under the same loading condition, the specimen with a gage length of $6.35 \mathrm{~mm}$ was deformed uniformly until necking occurred. However, due to the interaction between the high-intensity light for the DIC measurement and the laser system used 


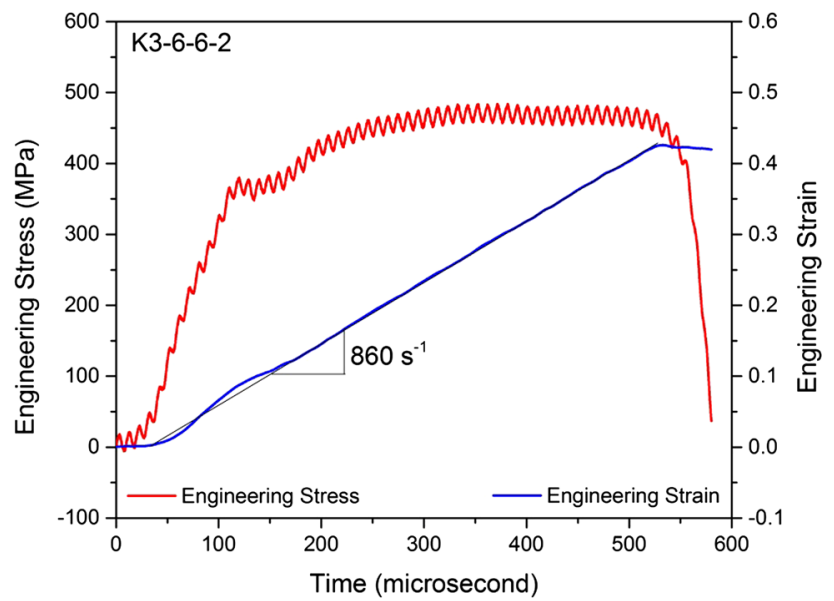

Fig. 8 Engineering stress and strain histories

for the direct strain measurement in the specimen, we were not able to apply DIC in each test. Based on the stress and strain histories shown in Fig. 8, the tensile stress-strain curves at $860 \mathrm{~s}^{-1}$ and $1030{ }^{\circ} \mathrm{C}$ were able to be obtained.

Following the same procedure, the iridium alloy was characterized in tension at two different strain rates $\left(\sim 1000\right.$ and $\left.3000 \mathrm{~s}^{-1}\right)$ and temperatures $(\sim 750$ and $1030{ }^{\circ} \mathrm{C}$ ). At each condition, three experiments were repeated and the results were consistent (within $10 \%$ ) at the same testing condition. Figure 9 shows the mean tensile stress-strain curves of the iridium alloy at different strain rates and temperatures. It is noted that, due to the superior ductility of the iridium alloy at elevated temperatures, the specimens did not fail during the first dynamic tensile load except for the testing condition of $735{ }^{\circ} \mathrm{C} / 3450 \mathrm{~s}^{-1}$. At the condition of $735{ }^{\circ} \mathrm{C} / 3450 \mathrm{~s}^{-1}$, the specimens possessed engineering failure strains varying between 0.5 and 0.7 . It

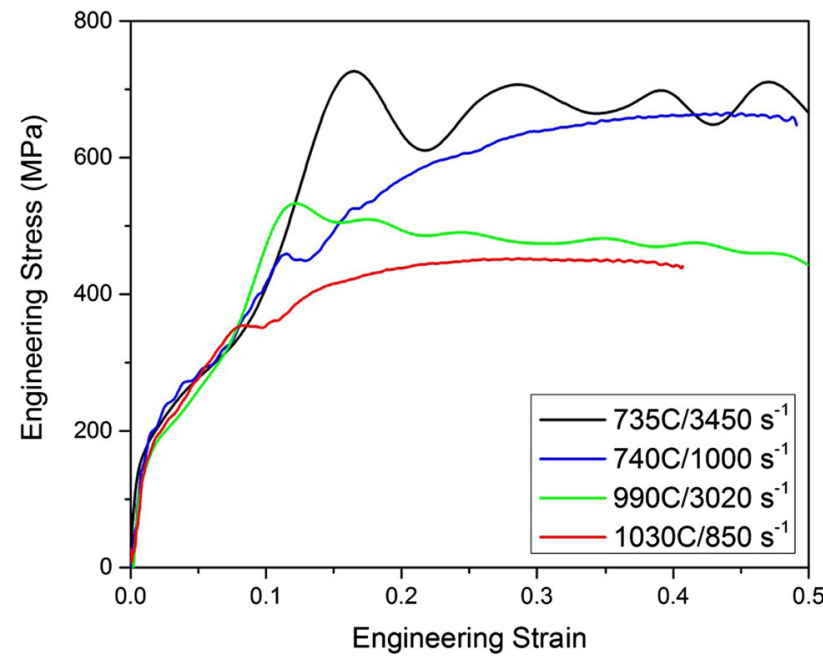

Fig. 9 Engineering stress-strain curves at different strain rates and temperatures is noted that the engineering failure strains were not representative of the actual failure strains since significant strain localization and necking occurred in the specimens before failure. Therefore, the stress-strain curves are plotted up to a strain of 0.5 in Fig. 9. It is noted that the stress-strain curve at $1030{ }^{\circ} \mathrm{C} / 850 \mathrm{~s}^{-1}$ ends at the strain of 0.4 due to unloading, not failure of the specimen. The dynamic high-temperature stress-strain curves of the iridium alloy show different profiles than quasi-static curves [3]. All stress-strain curves show an initial elasticity followed by significant work hardening behavior when the strain is below $10 \%$. This phenomenon may be related to a change in deformation mechanism at high strain rates and elevated temperatures, which is still under investigation. In addition, the stress-strain curve at $735{ }^{\circ} \mathrm{C} / 3450 \mathrm{~s}^{-1}$ had more oscillations than the others. The reason for this is still under investigation. When the strain is below $10 \%$, the stress-strain curves show neither strain-rate nor
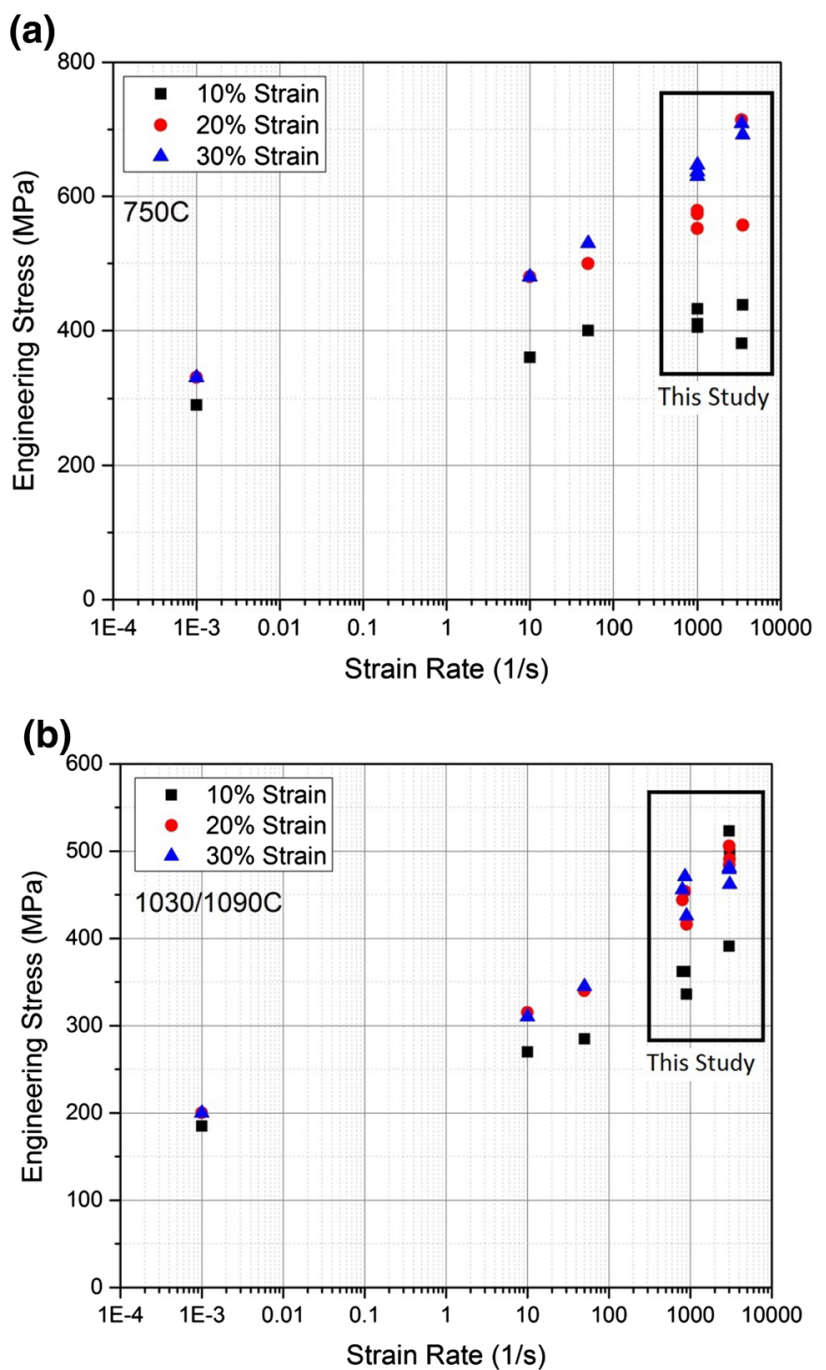

Fig. 10 Strain rate effect on the tensile stress-strain response at different temperatures. a $750{ }^{\circ} \mathrm{C}$; b 1030 or $1090{ }^{\circ} \mathrm{C}$ 
(a)

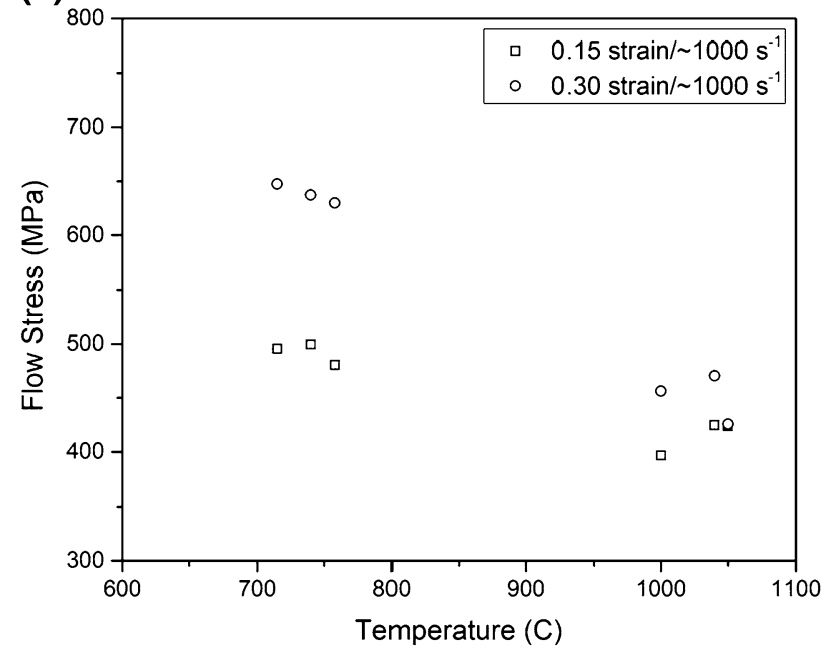

(b)

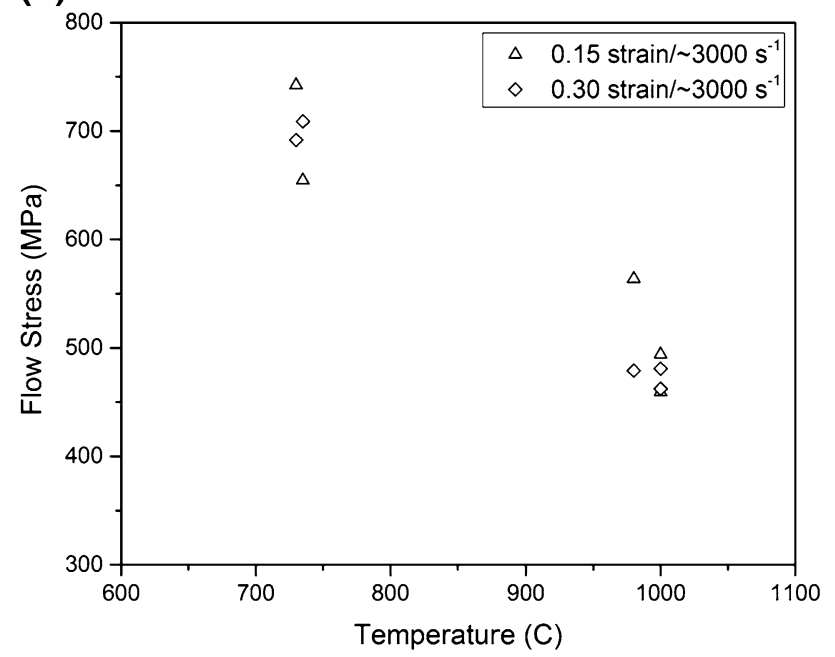

Fig. 11 Temperature effect on the tensile stress-strain response at different strain rates. $\mathbf{a} \sim 1000 \mathrm{~s}^{-1} ; \mathbf{b} \sim 3000 \mathrm{~s}^{-1}$

temperature effects. When the strain increases, the stressstrain curves show plastic flow with significant strain-rate and temperature effects. The insignificant work hardening behavior of the DOP-26 iridium alloy at high strain rates shown in Fig. 9 is consistent with the quasi-static data shown in Ref. [3] at similar high temperatures. At strains greater than $10 \%$ and similar strain rates the flow stresses decrease when the temperature increases from 750 to $1030{ }^{\circ} \mathrm{C}$, showing significant thermal-softening behavior. At the same temperature, the flow stresses increase when the strain rate increases from $\sim 1000$ to $3500 \mathrm{~s}^{-1}$, showing positive strain-rate sensitivity. Detailed strain-rate effects on the tensile stress-strain response including the quasi-static data at different strain rates and temperatures presented in Ref. [3] are shown in Fig. 10 at two different temperatures $\left(750{ }^{\circ} \mathrm{C}\right.$ (Fig. 10a) and $1030 / 1090{ }^{\circ} \mathrm{C}$ (Fig. 10b), respectively. The data obtained from this study were boxed and the rest are from the Ref. [3] in both figures. Figure 10 clearly shows a significant strain-rate effect on the tensile flow stress of the iridium alloy at both temperatures. The strain-rate sensitivities are slightly different at the two temperatures and are also dependent on the level of strain. Figure 11 shows the temperature effect on the flow stresses at the strains of 0.15 and 0.30 and two different strain rates $\left(\sim 1000\right.$ and $\left.3000 \mathrm{~s}^{-1}\right)$, respectively. The flow stresses decreased when the temperature increased from 750 to $1030{ }^{\circ} \mathrm{C}$, showing significant thermal softening behavior.

\section{Conclusion}

The conventional direct-tension Kolsky bar was modified for high-temperature tensile characterization of the DOP26 iridium alloy. An induction coil was applied to heat the iridium specimen to elevated temperatures up to $1030{ }^{\circ} \mathrm{C}$ while the specimen ends of the incident and transmission bars were cooled to reduce the thermal gradient in the bars. A pair of semiconductor strain gages on the transmission bar was used to directly measure the force/stress in the specimen during dynamic loading. A laser system was developed to independently measure the displacements at the specimen ends on the incident- and transmission-bar sides so that the specimen strain could be calculated. A spring-loaded pretension system was installed on the free end of the transmission bar to prevent the high-temperature specimen from buckling during heating. Dynamic tensile stress-strain curves of the iridium alloy were obtained at two elevated temperatures $\left(750\right.$ and $\left.1030{ }^{\circ} \mathrm{C}\right)$ and strain rates $\left(\sim 1000\right.$ and $\left.3000 \mathrm{~s}^{-1}\right)$. The iridium alloy shows high ductility at elevated temperatures and strain rates. The effects of strain rate and temperature on the tensile stressstrain response of the iridium alloy were also determined. The iridium alloy exhibited little sensitivity to strain rate or temperature when the strain was below $10 \%$ but strong sensitivities to both strain rate and temperature when the strain was greater than $10 \%$. The DOP-26 iridium alloy exhibited significant strain-rate hardening behavior at the same temperatures and thermal softening behavior at the same strain rates.

Acknowledgments The authors would like to acknowledge the support of Dr. Helena Jin for the preliminary DIC work and Kevin Connelly for his initial specimen and fixture design support. This work was sponsored by the United States Department of Energy (DOE) Office of Space and Defense Power Systems (NE-75). The authors gratefully acknowledge the support and guidance of Ryan D. Bechtel of the US Department of Energy. Sandia National Laboratories is a multi-program laboratory managed and operated by Sandia Corporation, a wholly owned subsidiary of Lockheed Martin Corporation, for the U.S. Department of Energy's National Nuclear Security Administration under contract DE-AC04-94AL85000. Oak 
Ridge National Laboratory is a multi-program research laboratory managed by UT-Battelle, LLC, for the US DOE under contract DEAC05-00OR22725.

\section{References}

1. Ohriner EK (2008) Processing of iridium and iridium alloys, methods from purification to fabrication. Platin Met Rev 52:186-197

2. George TG (1998) High-strain-rate, high-temperature biaxial testing of DOP-26 iridium, Los Alamos National Laboratory Report, LA-11065

3. Schneibel JH, Carmichael CA, George, EP (2007) High strain rate tensile testing of DOP-26 iridium, Oak Ridge National Laboratory Report, ORNL/TM-2007/81

4. McKamey CG, George EP, Lee EH, Ohriner EK, Cohron JW (2000) Impurity effects on high-temperature tensile ductility of iridium alloys at high strain rate. Scr Mater 42:9-15

5. George EP, Bei H, Lee EH, Braden JD (2004) Tensile impact ductility and fracture behavior of DOP-26 iridium at $500-900{ }^{\circ} \mathrm{C}$, Oak Ridge National Laboratory Report, ORNL/TM-2004/239

6. Song B, Nelson K, Lipinski R, Bignell J, Ulrich G, George EP (2014) Dynamic high-temperature testing of an iridium alloy in compression at high-strain rates. Strain 50:539-546

7. Song B, Nelson K, Lipinski R, Bignell J, Ulrich G., George EP (2014) Dynamic high-temperature characterization of an iridium alloy in compression at high strain rates, Sandia Report, SAND2014-15442

8. Kolsky H (1949) An investigation of the mechanical properties of materials at very high rates of loading. Proc $\mathrm{R}$ Soc Lond B62:676-700

9. Harding J, Wood EO, Campbell JD (1960) Tensile testing of materials at impact rates of strain. J Mech Eng Sci 2:88-96

10. Baker WE, Yew CH (1966) Strain-rate effects in the propagation of torsional plastic waves. J Appl Mech 33:917-923

11. Chen W, Song B (2011) Split Hopkinson (Kolsky) bar, design, testing and applications. Springer, New York

12. Kawata K, Hashimoto S, Kurokawa K, Kanayama N (1979) A new testing method for the characterization of materials in highvelocity tension, In: J. Harding J (ed), Mechanical properties at high rates of strain, institute of physical conference series, vol 47. p 71-80
13. Owens AT, Tippur HV (2009) Tensile stress-strain response of glass-filled epoxy under elevated rates of loading using a split Hopkinson bar apparatus. Exp Mech 49:799-811

14. Song B, Antoun BR, Connelly K, Korellis J, Lu W-Y (2011) Improved Kolsky tension bar for high-rate tensile characterization of materials. Meas Sci Technol 22:045704

15. Su J, Guo W, Meng W, Wang J (2013) Plastic behavior and constitutive relations of DH-36 steel over a wide spectrum of strain rates and temperatures under tension. Mech Mater 65:76-87

16. Guo W-G, Gao X (2013) On the constitutive modeling of a structural steel over a range of strain rates and temperatures. Mater Sci Eng A 561:468-476

17. Feng F, Huang S, Meng Z, Hu J, Lei Y, Zhou M, Wu D, Yang Z (2014) Experimental study on tensils property of AZ31B magnesium alloy at different high strain rates and temperatures. Mater Des 57:10-20

18. Whittington WR, Oppedal AL, Turnage S, Hammi Y, Rhee H, Allison PG, Crane CK, Horstemeyer MF (2014) Capturing the effect of temperature, strain rate, and stress state on the plasticity and fracture of rolled homogeneous armor (RHA) steel. Mater Sci Eng A 594:82-88

19. Vilamosa V, Clausen AH, Fagerholt E, Hopperstad OS, Børvik T (2014) Local measurement of stress-strain behaviour of ductile materials at elevated temperatures in a split-Hopkinson tension bar system. Strain 50:223-235

20. Guzman O, Frew DJ, Chen W (2011) A Kolsky tension bar technique using a hollow incident tube. Meas Sci Technol 22:045703

21. Rosenberg Z, Dawicke D, Strader E, Bless SJ (1986) A new technique for heating specimens in split-Hopkinson-bar experiments using induction-coil heaters. Exp Mech 26:275-278

22. Scapin M, Peroni L, Fichera C (2014) Investigation of dynamic behaviour of copper at high temperature. Mater High Temp 31:131-140

23. Song B, Antoun BR, Jin H (2013) Dynamic tensile characterization of a 4330-V steel with Kolsky bar techniques. Exp Mech 53:1519-1529

24. Nie X, Song B, Loeffler CM (2015) A novel splitting-beam laser extensometer technique for Kolsky tension bar experiment. J Dyn Behavi Mater 1:70-74

25. Song B, Lu W-Y (2012) Preload high-rate tension techniques, In: Proceedings of SEM XII international congress and exposition on experimental and applied mechanics, Costa Mesa 